\title{
Financiamento do ensino médio: transparência ou opacidade?
}

\section{Resumo}

Este trabalho focaliza a precariedade do financiamento do ensino médio público e a falta de transparência dos seus dados. Como outros níveis e modalidades da educação básica, o ensino médio é dependente do ensino fundamental e necessita de soluções não raro improvisadas para assegurar recursos. A expansão da matrícula levou ao agravamento deste quadro, o que se evidencia no caso do Distrito Federal, onde uma pesquisa traçou o perfil do seu financiamento e orçamentação. Os dados foram obtidos por meio de dados estatísticos agregados, análise documental e entrevistas semi-estruturadas. Os resultados indicam a contribuição crescente do Tesouro do Distrito Federal para o ensino médio, constatando-se, em geral, grandes variações anuais de recursos e valores subestimados para esse nível de ensino. $O$ PROMED, com suas dificuldades burocráticas, alcançou até então modesto impacto. Por isso mesmo, o FUNDEB exige estimativas claras e desagre- gadas das despesas e dos custos do ensino médio, de modo que o financiamento e os seus resultados possam ser conhecidos com transparência.

Palavras-chave: Financiamento da educação. Economia da educação. Ensino Médio. Distrito Federal. Custos educacionais. Despesas educacionais.

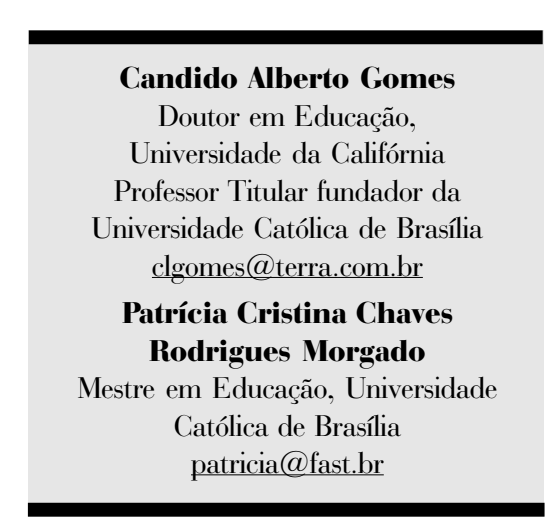

\section{Abstract Secondary education financing: transparency or opacity?}

This paper focuses on the precarious financing of public secondary education and the need of clear, transparent data. As other levels of
schooling, secondary education largely depends on primary education sources, often requiring improvised alternatives to assure resources. Enrollment expansion has led to more serious problems. A field research studied the financing and budgeting processes of public secondary 
education in the Federal District. Data were collected from statistical sources, document analysis, and semi-structured interviews. Results reveal the increasing contribution of the District own income, instead of the federal transfers. The amount of resources largely varied per year. Furthermore, secondary education expenditure data were systematically underestimated in accountancy. An international program had small impact, as a result of bureaucratic obstacles. Therefore, the new national fund to finance basic education requires clear and disaggregated estimates of spending and costs so that financing and results reach transparency.

Keywords: Education financing. Economics of education. Secondary education. Brazil. Educational costs. Educational expenditure.

\section{Resumen}

\section{Financiamiento de la} educación secundaria:

\section{¿̇transparencia 0 opacidad?}

Este trabajo trata de la precaridad del financiamiento de la educación secundaria pública, así como de la falta de transparencia de los números. Como otros niveles de la educación básica, la secundaria es financieramente dependiente de la educación primaria $y$, en consecuencia, necesita de soluciones improvisadas para garantizar sus recursos. La expansión de la matrícula agravó esta situación, lo que se evidencia en el caso del Distrito Federal. Una investigación describió y analisó sus procesos de financiamiento y elaboración del presupuesto. Además de las estadísticas disponibles, se obtuvieron los datos por análisis de documentos y entrevistas semiestructuradas. Los resultados apuntan la creciente contribución de los recursos propios del Districto Federal para la educación secundaria. Se verificaron amplias variaciones anuales de recursos y subestimación contable de la plata para la educación secundaria. Un programa internacional tuvo escaso impacto, como consecuencia de su compleja burocracia. Como consecuencia, el nuevo fondo nacional de financiamiento para toda la educación básica requiere estimativas claras y detalladas de los gastos y de los costos de la educación secundaria. Este es el camino para que el financiamiento y los resultados sean conocidos con claridad.

Palabras clave: Financiación de la educación. Economía de la educación. Educación secundaria. Brasil. Gastos educativos. Costos educativos.

A busca de soluções mais duradouras para o financiamento da educação básica situa no centro das discussões a falta de dados adequados sobre o ensino médio. Este, junto com a educação infantil, a educação especial e a educação de jovens e adultos, se inserem no financiamento público de modo apendicular: enquanto o tronco ainda é o ensino fundamental obrigatório, tanto na contabilidade quanto nas fontes de recursos, as etapas e modalidades citadas da educação básica ainda giram como mariposas em torno do ensino fundamental. A prioridade assegurada a este pelo Fundo de Manutenção e Desen- 
volvimento do Ensino Fundamental e de Valorização do Magistério - FUNDEF, e a relativa exclusividade do salário-educação, até 2006, levou à satisfação de demandas socioeconômicas por intermédio de "anexos". Parte dos prédios e do pessoal foi financiada pelo ensino fundamental, com a cessão de espaços geralmente ociosos ou acrescentados aos projetos e a utilização de parte do tempo docente e não docente em outros níveis e modalidades da educação básica. Assim, o tronco ou a locomotiva que puxava os carros era 0 ensino fundamental, o que se patenteia também nas transferências intergovernamentais (GOMES, 1992). Por isso mesmo, os dados contábeis, se tomados formalmente, permitir-nos-iam concluir que o valor médio da despesa aluno/ano no ensino médio é muito inferior ao do ensino fundamental (GOMES, 1998), levando à opacidade, em vez da transparência.

Esta dificuldade se acentuou com a acelerada expansão desse nível de ensino nos últimos anos, conforme assinala Costa (2001). Por fatores demográficos, aumento da produtividade, elevação da cobertura do ensino fundamental e outros fatores, o ensino médio, até aqui o "patinho feio", pode alcançar identidade própria e tornarse um cisne. Assim, no sistema de vinculação de recursos cabia-lhe teoricamente o mínimo de dez por cento da receita líquida de impostos dos Estados, o que não seria desprezível. Existiam e continuam a existir, porém, a concorrência da educação superior estadual e uma rede de subvinculações, antes do FUNDEF, agora do Fundo de Manutenção e Desenvolvimento da Educação Básica e de Valorização dos Profissionais da Educação - FUNDEB, além de medidas protetoras da educação superior, que conferem pouca flexibilidade à alocação de recursos, tornando o ensino médio dependente do aumento das verbas totais destinadas à educação nos Estados.

Trabalho de Davies (2004) mostrou que o montante de recursos alocado pelo MEC estava longe de garantir as preconizadas expansão e melhoria da qualidade. A sua proposta, por carência de recursos compatíveis, era frágil e secundarizava a qualidade, correspondendo à política de congelamento e/ou de redução dos gastos públicos. Foi o que constatou Santos (2004) quanto à redução dos recursos governamentais para as Escolas Técnicas Federais e Centros Federais de Educação Tecnológica - CEFETs, em obediência a ajustes macroeconômicos e à transferência de recursos do Ministério da Educação - MEC, para Estados e Municípios, no período de 1995 a 2003. Igualmente, destacou a tendência dos governos no sentido de gastar menos por aluno, apesar dos discursos oficiais. Apontou como desafios o privatismo direto e indireto das políticas oficiais, o descumprimento da vinculação de recursos à manutenção e desenvolvimento do ensino, a falta de confiabilidade dos Tribunais de Contas, a exclusão do ensino médio do FUNDEF e a reduzida contribuição federal para o ensino médio.

segundo plano, que tem sido atribuído à qualidade, foi objeto de análise de Pinto (2004). Suas constatações indicam que a rápida expansão do ensino médio foi acompanhada pela queda do gasto por aluno como percentual do Produto interno bruto PIB, per capita. Assinala, ainda, as disparidades de gastos por região e dependência administrativa, bem como, segundo uma pesquisa do MEC, entre estabelecimentos. 
Segundo esta última, os custos indiretos alcançaram elevada proporção, enquanto os custos com direção e pessoal em sala de aula ficaram em torno de $60 \%$ do total. Desenhando uma escola média de qualidade, estimou que o custo total por aluno/ano seria bem maior que o então praticado, exigindo, conseqüentemente volumosos recursos financeiros para atingir as metas do Plano Nacional de Educação - PNE.

Estas dificuldades se refletem e se reiteram ao nível das escolas. Maldi e Gomes (2003) constataram em três Unidades Federativas que o ensino médio era altamente dependente de recursos da comunidade e da capacidade de arrecadação promovida pelo diretor, que precisava de alta capacidade de liderança. Apesar do desprivilégio social de grande parte do alunado, os programas da merenda escolar e do livro didático encontravam-se restritos ao ensino fundamental, criando graves dilemas para as escolas. Desse modo, não sendo compulsório, o ensino médio sofria discriminação negativa ou precisava valer-se regressivamente de recursos comunitários (isto é, tão mais volumosos quanto mais alta a renda da comunidade e vice-versa) ou de "desvios" dos recursos privativos do ensino fundamental, que em certos casos conduziam a inquéritos administrativos.

Se a cobertura dos custos diretos apresenta estas dificuldades num nível de ensino com elevado crescimento de matrículas, Cavalcante (2002) investigou os custos indiretos dos alunos do ensino médio público do Distrito Federal. Seus resultados mostraram que a rede apresenta alto grau de acesso, porém a amostra estudada apresentou-se relativamente homogênea no seu baixo nível de renda. Dessa forma, os custos indiretos, a car- go dos discentes e suas famílias, eram onerosos para o seu orçamento familiar, especialmente quanto ao livro didático. $\bigcirc$ autor verificou que os custos indiretos correspondiam a $58,7 \%$ dos custos diretos por aluno, isto é, de funcionamento da escola. Os custos indiretos reais, na faixa de renda mais baixa, ficavam $28,1 \%$ abaixo do valor padrão fixado para as necessidades mínimas dos alunos e situavamse $79,6 \%$ abaixo do valor padrão na faixa de renda mais alta. Portanto, a gratuidade da escola pública é necessária, mas não suficiente para assegurar a democratização com qualidade do ensino médio.

\section{O caso do Distrito Federal}

Distrito Federal - DF, é um caso menos típico dentre as Unidades Federativas, entre outros motivos por não se dividir em municípios e por contar com o Fundo Constitucional do Distrito Federal - FCDE, que provê recursos federais para a manutenção da segurança pública, saúde e educação na Capital da República. No entanto, dando continuidade ao programa de pesquisa sobre o ensino médio do Mestrado em Educação da Universidade Católica de Brasília (que produziu várias pesquisas acima citadas), Morgado (2005) desenvolveu um projeto com o objetivo de traçar o perfil do financiamento e da orçamentação deste nível de ensino na Secretaria de Estado de Educação do Distrito Federal - SEDF. A metodologia utilizada envolveu a análise documental da legislação, normas, manuais, planos, balanços, balancetes, relatórios e outros documentos, bem como a realização de entrevistas semi-estruturadas com gestores da SEDF, representantes do Poder Legislativo e de organizações internacionais. A coleta de dados ocorreu no segundo semestre de 2004. 
Este trabalho abordará tão-somente o processo de financiamento, enquanto a orçamentação será objeto de outro relatório.

Os resultados indicam inicialmente que, apesar do FCDF, a SEDF, no período analisado, passou a depender cada vez mais dos recursos do Tesouro do Distrito Federal, incluindo especialmente a receita própria e as transferências constitucionais devidas a Estados e municípios (Fundos de Participação dos Estados e dos Municípios - FPE e FPM), salário-educação e outros. Assim, em 2001 o FCDF era responsável por 79,8\% dos valores dos repasses, enquanto os do Tesouro do DF correspondiam a 20,2\%. Em 2003 estes percentuais passaram, respectivamente, para $58,9 \%$ e $41,1 \%$. $\bigcirc$ fato de ser indivisível em municípios não exime a Unidade Federativa da obrigatoriedade do FUNDEF, de modo a priorizar o ensino fundamental com 15\%, no mínimo, da receita dos impostos específicos.

Desagregando as fontes do orçamento empenhado em 2003 na tabela 1, verifica-se que a maioria dos recursos destinados à manutenção da Administração Geral da SEDF, incluindo o pagamento de ativos e contratados por tempo determi- nado, provém do FCDF. No caso do pagamento de inativos e pensionistas, a proporção do Tesouro do DF é maior, sendo apenas $2,7 \%$ do total cobertos pelas contribuições de empregadores e trabalhadores, um dado preocupante para o presente e o futuro da previdência social. Já a educação infantil, não contando com o FUNDEF, teve a cobertura de mais da metade das despesas pelo Tesouro do DF. $O$ ensino fundamental contou com fontes mais diversificadas, tendo à frente o Tesouro - Cota do FUNDEF e o salário-educação. $\bigcirc$ ensino médio, por sua vez, teve a mais alta proporção de recursos do Tesouro do DF, quase dois terços, seguida do FCDF e de apenas 2,8\% resultantes de convênios com outros órgãos, entre eles o Programa de Melhoramento e Expansão do Ensino Médio - PROMED, que será abordado adiante. Esta fragilidade relativa, como se verá, parece ainda maior na medida em que uma proporção expressiva das despesas do ensino médio, bem como da educação infantil, supostamente, do ponto de vista contábil, é atribuída ao ensino fundamental. Por fim, a educação profissional era financiada primordialmente pelo FCDF. 


\section{Tabela 1 - Orçamento empenhado por fonte, 2003.}

\begin{tabular}{|c|c|c|}
\hline & $\begin{array}{l}\text { Aplicado } \\
\text { (Valores } \\
\text { Nominais) } \\
\end{array}$ & $\begin{array}{c}\text { Aplicado } \\
\text { (Valores de } 2004 \\
\text { IGP-DI/FGV) }\end{array}$ \\
\hline Despesas do Exercício & $1.676 .192 .133,57$ & $1.833 .754 .194,13$ \\
\hline Despesas do Exercício Anterior & $154.116 .091,05$ & $168.603 .003,61$ \\
\hline Total Empenhado & $1.830 .308 .224,62$ & $2.002 .357 .197,73$ \\
\hline Fonte 100 - Tesouro do GDF & $284.186 .963,75$ & $310.900 .538,34$ \\
\hline Fonte 102 - Fundo de Participação dos Municípios & $3.697 .250,94$ & $4.044 .792,53$ \\
\hline Fonte 103 - Contribuição do Salário Educação & $61.525 .368,67$ & $67.308 .753,32$ \\
\hline Fonte 105 - Transferência de Imposto Territorial Urbano & $160.000,00$ & $175.040,00$ \\
\hline Fonte 106 - Contrib. Empregadores e Trab. P/ Seguridade Social & $1.533 .640,00$ & $1.677 .802,16$ \\
\hline Fonte 121 - Aplicações Financeiras Vinculadas (Convênios) & $117.471,32$ & $128.513,62$ \\
\hline Fonte 130 - Transferência da União (FCDF) & $1.057 .870 .313,73$ & 1.157.310.123,22 \\
\hline Fonte 132 - Convênios Outros Órgão (Não Integrantes do GDF) & $2.068 .890,43$ & $2.263 .366,13$ \\
\hline Fonte 140 - Programa Nacional de Alimentação Escolar & $9.414 .627,35$ & 10.299.602,32 \\
\hline Fonte 141 - Programa Dinheiro Direto na Escola & - & \\
\hline Fonte 303 & $3.713 .202,84$ & $4.062 .243,91$ \\
\hline Fonte 321 & $86.734,85$ & $94.887,93$ \\
\hline Fonte 332 & $801.105,73$ & $876.409,67$ \\
\hline Fonte 340 & $415.088,90$ & $454.107,26$ \\
\hline Fonte 100 - Fundef & $367.007 .617,47$ & $401.506 .333,51$ \\
\hline Fonte 101 - Fundef & $29.035 .391,96$ & $31.764 .718,80$ \\
\hline Fonte 102 - Fundef & $8.647 .429,32$ & $9.460 .287,68$ \\
\hline Fonte 109 - Fundef & $27.127,36$ & $29.677,33$ \\
\hline
\end{tabular}

Fonte: SEDF (2004).

A evolução da execução orçamentária (tabela 2) reitera as constatações anteriores da literatura, que indicam pequenas dotações para o ensino médio e concentração no ensino fundamental. Em face da existência de recursos vinculados a este último, confirma-se o seu papel de tronco mantenedor de diversos ramos da educação básica. A subvinculação podia não só contribuir para superestimar as despesas, a fim de cumprir as formalidades legislativas (as vinculações, então, incentivariam as maquiagens e os desvios?), como também se deve considerar a difi- culdade de desagregação das despesas quando se concentra no mesmo estabelecimento mais de uma etapa da educação básica, com a incidência maior naqueles que simultaneamente oferecem o ensino fundamental e médio completos (GOMES, 2000). As oscilações dos valores reais indicam mudanças abruptas, com encolhimento e expansão dos recursos de um ano para outro, o que pode levar a difíceis decisões de corte e emprego de acréscimos de verbas. Segundo a literatura, a qualidade da alocação tende a se reduzir em face destes movimentos mais bruscos 
Tabela 2 - Execução orçamentária da SEDF, 1998-2003.

\begin{tabular}{|c|c|c|c|c|}
\hline \multirow[b]{2}{*}{ Programa Orçamentário } & \multicolumn{2}{|c|}{1998} & \multicolumn{2}{|c|}{1999} \\
\hline & Executado & $\begin{array}{l}\text { \% Executado/ } \\
\text { Autorizado }\end{array}$ & Executado & $\begin{array}{r}\% \text { Executado/ } \\
\text { Autorizado }\end{array}$ \\
\hline Administração & $485.328,98$ & $89,10 \%$ & $593.822,76$ & $77,43 \%$ \\
\hline Educação Infantil & $4.795,43$ & $67,57 \%$ & 850,08 & $4,84 \%$ \\
\hline Ensino Fundamental & $996.297,50$ & $93,15 \%$ & $721.559,13$ & $67,48 \%$ \\
\hline Ensino Médio & $3.474,02$ & $52,13 \%$ & $2.010,33$ & $3,96 \%$ \\
\hline Ensino Superior & 2,13 & $1,00 \%$ & - & $0,00 \%$ \\
\hline EJA & 127,88 & $30,30 \%$ & 126,36 & $32,35 \%$ \\
\hline Educação Especial & 230,18 & $64,29 \%$ & 884,55 & $16,61 \%$ \\
\hline Ensino Profissional & - & $0,00 \%$ & - & $0,00 \%$ \\
\hline & \multicolumn{2}{|c|}{2000} & \multicolumn{2}{|c|}{2001} \\
\hline Programa Orçamentário & Executado & $\begin{array}{r}\% \text { Executado/ } \\
\text { Autorizado }\end{array}$ & Executado & $\begin{array}{r}\% \text { Executado/ } \\
\text { Autorizado } \\
\end{array}$ \\
\hline Administração & \multirow{8}{*}{$\begin{array}{l}\text { Dados não } \\
\text { fornecidos }\end{array}$} & \multirow{8}{*}{$\begin{array}{l}\text { Dados não } \\
\text { fornecidos }\end{array}$} & $168.993,58$ & $92,53 \%$ \\
\hline Educação Infantil & & & $58.974,69$ & $99,15 \%$ \\
\hline Ensino Fundamental & & & $1.060 .146,17$ & $97,00 \%$ \\
\hline Ensino Médio & & & $169.768,18$ & $99,11 \%$ \\
\hline Ensino Superior & & & - & $0,00 \%$ \\
\hline EJA & & & 68,62 & $33,09 \%$ \\
\hline Educação Especial & & & 47,27 & $100,00 \%$ \\
\hline Ensino Profissional & & & $51.622,10$ & $99,91 \%$ \\
\hline & \multicolumn{2}{|c|}{2002} & \multicolumn{2}{|c|}{2003} \\
\hline Programa Orçamentário & Executado & $\begin{array}{r}\% \text { Executado/ } \\
\text { Autorizado } \\
\end{array}$ & Executado & $\begin{array}{r}\% \text { Executado/ } \\
\text { Autorizado }\end{array}$ \\
\hline Administração & $168.748,50$ & $97,96 \%$ & $168.951,89$ & $98,52 \%$ \\
\hline Educação Infantil & $71.404,40$ & $88,98 \%$ & $5.872,59$ & $93,70 \%$ \\
\hline Ensino Fundamental & $981.012,48$ & $93,92 \%$ & $608.125,06$ & $92,91 \%$ \\
\hline Ensino Médio & $163.931,07$ & $88,86 \%$ & $24.480,44$ & $92,93 \%$ \\
\hline Ensino Superior & - & $0,00 \%$ & - & $0,00 \%$ \\
\hline EJA & 60,45 & $27,27 \%$ & 423,38 & $79,14 \%$ \\
\hline Educação Especial & 1,34 & $0,08 \%$ & 426,66 & $91,55 \%$ \\
\hline Ensino Profissional & $52.028,54$ & $99,85 \%$ & $2.306,15$ & $89,86 \%$ \\
\hline
\end{tabular}

Fonte: TCDF (1998-2003).

Valores de 2004 atualizados pelo IGP-DI/FGV em R\$1.000,00 
(GOMES, 1995). Assim, por exemplo, o total de 2003 foi aparentemente igual a $56,4 \%$ do valor de 2002 . Por sua vez, os percentuais de execução em face dos valores autorizados deixam nítido que a principal prioridade foi o ensino fundamental, uma vez que este nível de ensino abrangeu, em média, no período analisado, $65,9 \%$ da execução orçamentária. A segunda maior dotação orçamentária foi a administração (incluindo pessoal ativo, inativo, contratados temporariamente e pensionistas), abrangendo em média $24,3 \%$ do orçamento executado. Sendo de caráter geral, nesta se incluíam provavelmente despesas diretas e indiretas do ensino médio. Este último ocupou o terceiro lugar (5,2\% em média), seguido pela educação infantil, educação de jovens e adultos - EJA, e educação especial. No período em tela a dotação orçamentária do ensino médio cresceu 323,7\%, fato explicado pelo início da execução do PROMED.

Os enganos a que pode levar a contabilidade pública podem ser observados na tabela 3, que apresenta a despesa média por aluno conforme os programas orçamentários. Podem-se observar valores relativamente altos para a despesa média dos alunos do ensino fundamental e valores muito baixos para os alunos da educação infantil e ensino médio em alguns anos e bem maiores em outros anos. Para a educação de jovens e adultos, os valores encontrados são mínimos. Para a educação especial os valores também são muito reduzidos, além de inconstantes. No caso da educação profissional, em certos exercícios financeiros os dados não foram apresentados, ao passo que em outros os valores foram relativamente altos.

Tabela 3 - Despesa média (em R\$) por aluno da SEDF, 1998-2003.

\begin{tabular}{|c|c|c|c|c|c|c|}
\hline \multicolumn{7}{|c|}{ Despesa Aluno } \\
\hline Programa & 1998 & 1999 & 2000 & 2001 & 2002 & 2003 \\
\hline Educação Infantil & 222,71 & 36,26 & \multirow{6}{*}{\begin{tabular}{ll}
0 & 0 \\
10 & 0 \\
\multicolumn{1}{c}{} & 0 \\
s. \\
0 \\
0 & 0 \\
0 & 0 \\
0 & 0 \\
0 & 0
\end{tabular}} & $1.558,40$ & $1.757,82$ & 129,63 \\
\hline Ensino Fundamental & $2.888,88$ & $2.114,69$ & & $3.432,55$ & $3.261,01$ & $2.072,42$ \\
\hline Ensino Médio & 39,69 & 19,94 & & $1.587,02$ & $1.518,91$ & 241,22 \\
\hline EJA & 1,55 & 1,54 & & 0,73 & 0,67 & 4,54 \\
\hline Educação Especial & 37,73 & 144,98 & & 9,66 & 0,23 & 46,61 \\
\hline Ensino Profissional & 0,00 & 0,00 & & $18.024,48$ & $17.805,80$ & 591,17 \\
\hline
\end{tabular}

Fonte: TCDF e SEDF (1998-2003)

Atualização: IGP-DI FGV

As pequenas dotações para o ensino médio e outros programas orçamentários sugerem que grande parte das suas despesas era incluída em Administração (pessoal ativo e inativo) e, provavelmente, no ensino fundamental. De fato, como mostra a tabela 3, ao se dividir a matrícula do ensino fun- damental público de 2003 por suas dotações específicas obteve-se a média de R\$ 2.072,42 por aluno. Caso se utilize o mesmo procedimento para o ensino médio, se alcançará $\mathrm{R} \$ 241,22$. Uma vez somadas as despesas de administração e de ensino fundamental, chegar-se-á a R\$2.648,00 por 
aluno e a $R \$ 1.906,00$ por aluno, este no caso do ensino médio. Ao se dividir o total do valor executado em 2003 pelo número total de alunos da rede pública do Distrito Federal se chegará a $\mathrm{R} \$ 1.483,00$. Certamente uma parte do gasto do ensino médio estava incorporada ao ensino fundamental.

Castro e Duarte (2003?) estimaram o gasto mínimo por aluno/ano, em preços de 2003, respectivamente em $\mathrm{R} \$ 440,00$ e $\mathrm{R} \$ 572,00$ para o ensino fundamental e médio. Quanto a 2003, em consonância com as metas do PNE, foram projetados valores segundo dois cenários, acompanhando a provável evolução do PIB: A) refletindo o gasto mínimo por aluno/ano aplicado pelo FUNDEF para os alunos do ensino fundamental em 2003; B) um cenário hipotético, cujo valor mínimo seria igual ao valor potencial médio brasileiro, dadas as estimativas dos orçamentos educacionais de Estados e municípios e de suas respectivas matrículas nos níveis e modalidades da educação básica em 2003.

Em ambos os cenários, os gastos por aluno/ano do ensino médio foram estimados como $30 \%$ superiores aos gastos dos alunos do ensino fundamental (visto que o salário-aula tende a ser mais alto, o currículo mais extenso e os equipamentos mais exigentes). Com isso, os autores estimaram, para 2003, o gasto aluno/ano do ensino fundamental em $\mathrm{R} \$ 475,00$ e $\mathrm{R} \$ 740,00$ (cenários $\mathrm{A}$ e $\mathrm{B}$, respectivamente) e o gasto aluno/ano do ensino médio em $\mathrm{R} \$ 618,00$ e $R \$ 962,00$ (cenários $A$ e $B$, respectivamente). Assim, os recursos projetados para atender à demanda pelo ensino médio do Distrito Federal em 2003 seriam de R\$ 66.982.695,00 e R\$104.351.988,00 respectivamente para os cenários $A$ e $B$.
Fica claro que as médias de execução de recursos do Distrito Federal por aluno são muito mais altas que as médias nacionais estimadas de gastos mínimos, o que guarda correspondência não só com o PIB do Distrito Federal, mas também com os recursos do FCDF.

\section{O PROMED: boas intenções no labirinto burocrático}

A rápida expansão do ensino médio e a aprovação, em 1998, das Diretrizes Curriculares Nacionais do Ensino Médio levaram o MEC a elaborar o PROMED ou Projeto Escola Jovem, no valor de US\$ 1 bilhão, financiado por empréstimo do Banco Interamericano de Desenvolvimento BID (US\$ 500 milhões), a ser pago pela União, somado a uma contrapartida nacional equivalente a US\$50 milhões do Tesouro Nacional e US\$ 450 milhões das Unidades Federativas. O Distrito Federal aderiu ao Programa ao fim de 2001 . 0 Convênio assinado naquele ano encontrava-se, em 2004, no sexto Termo Aditivo. De acordo com o primeiro, o MEC ficou responsável por $60 \%$ dos recursos e o Distrito Federal por 40\%. O segundo Convênio, de 2004, com execução simultânea ao primeiro, inverteu aquelas participações percentuais, passando o Distrito Federal a arcar com $60 \%$ do total.

Segundo depoentes, as ações de maior impacto até o período da coleta de dados foram a ampliação/construção de cinco salas de aula e uma reforma em uma das escolas exclusivas de ensino médio. Destacaram-se também alguns processos de capacitação, que alcançaram numerosos professores. 
No entanto, foi percebido como grande dificuldade para a execução eficaz do Programa a elevada evasão dos professores dos cursos de capacitação oferecidos. Segundo um depoente, foi oferecido um curso a distância, com os recursos do PROMED, onde no início, havia dez turmas de aproximadamente trinta professores, e, ao final, menos de $50 \%$ dos professores concluíram a capacitação: "O curso foi oferecido à distância, com 180 horas, uma carga horária razoável, mas poucos professores tiveram a persistência de chegar até o final", afirmou um depoente. Não foram obtidos dados seguros sobre os motivos dessa alta evasão.

As ações de modo geral foram muito modestas, inclusive, conforme se verá, pelo atraso dos recursos. Estabeleceu-se então um hiato entre o pretendido e o realizado, perdendo-se o vigor de um possível impacto e a efetivação de ações necessárias à renovação do ensino médio.

Além da evasão dos professores, foram relatadas por depoentes, como outras grandes dificuldades na execução do Convênio, as excessivas regras e os trâmites burocráticos impostos pelo BID para as licitações. $O$ referido Banco exige que as compras sejam feitas exatamente como programadas, mas, segundo relatos, isso não acontece:

Por exemplo, eu programei hoje comprar um microcomputador por $\mathrm{R} \$ 3.000$, daqui a dois meses esse microcomputador já não custa mais esse valor. Então, nós não temos a flexibilidade de adquirir o microcomputador pelo valor atualizado, mesmo que o dinheiro seja da contrapartida [...]. Temos que, primeiro, submeter à apreciação do MEC e eles, por sua vez, à do BID, para que essa aquisição seja feita, o que deixa lento o processo.

Trata-se de legislação e normas, sobretudo nacionais, que parecem talhadas para retardar e dificultar o gasto público, supostamente contribuindo para combater o deficit governamental. No entanto, os resultados são contraproducentes porque as despesas realizadas a conta-gotas deixam de gerar os impactos esperados. Em outras palavras, neste exemplo de que o barato pode sair caro, as restrições indiscriminadas tendem a reduzir a produtividade e a efetividade.

Outra dificuldade relatada foi a programação de muitas ações para um só convênio, muito fragmentadas, numerosas e simultâneas, que não tornavam viáveis sua execução. Buscou-se corrigir esta dificuldade no segundo Convênio, estabelecendo-se menos ações, mas de impacto e que contribuíssem realmente para mudanças. Têm-se, então, seis ou sete grandes ações para o novo Convênio. Tal dificuldade fica clara no relato de outro depoente:

Por exemplo, eu comecei um processo para adquirir livros, coloquei todos os livros naquele processo. Aí, vai lá na licitação, compram cinco livros, aí volta para mim, pagam à empresa, depois voltam e iniciam um novo processo de licitação para comprar o restante. Há falhas, às vezes, aparecem algumas empresas para participar da licitação que não têm todos aqueles livros, ou então ocorre falha na descrição da licitação. Hoje, nós não temos mais tanto esse problema na publicação do edital, mas já tivemos 
muito. Por exemplo, publicar material de laboratório de física, química e biologia como se fosse material de laboratório de análises clínicas. Então, isso já é uma falha; quando ocorre, tem que começar todo o processo para poder corrigir na hora da publicação, porque as empresas que vão aparecer com esse processo de licitação são as de laboratório de análises clínicas. Por isso, muitas vezes, ocorrem falhas, ou na descrição de material, ou na alteração de preço, fazendo com que o material tenha que voltar. Nesse meio tempo, nós já tivemos três períodos de eleição onde os processos têm que, de certa forma, tramitar mais devagar porque o Governo Federal não pode fazer repasse nenhum para os Estados e o Distrito Federal, por conta da lei de orçamento, que não permite fazer repasses em período eleitoral. Então, a gente tem que dar uma brecada nos processos; aí acaba que um processo que estava lá atrás começa a tramitar com um que está lá na frente. Todos esses problemas atrapalham.

Sobre o relacionamento da SEDF com - MEC, afirmou-se que já foi mais difícil, mas que então era "mais tranqüilo!": "Eles estão mais acessíveis, estão mais próximos de nós, estão com mais vontade de acertar junto com a gente", foi afirmado.

Apesar das dificuldades apresentadas, esta é uma típica avaliação positiva dos depoentes:

ensino médio não tinha nada, as ações voltadas para o ensino médio eram mínimas. Existiam, mas eram tão raras que os governos, de um modo geral, não estavam preparados para a execução. Não existia programação para o ensino médio inicialmente. Esse projeto ajudou e ajuda bastante. Nesse novo Convênio, nós temos, além de uma capacitação em nível de pós-graduação, a aquisição de equipamentos de informática para montagem de laboratórios de informática, que é um anseio não só dos alunos, mas também dos professores e, de um modo geral, não só do Distrito Federal, mas do Brasil todo. Está muito voltado para essa questão da tecnologia de um modo geral. Uma outra aquisição feita foi de equipamentos que a gente chama de multimídia, projetor multimídia, retroprojetor, DVD, vídeo cassete, televisões, vídeos, todos esses equipamentos que fazem diferença na prática pedagógica, que ajudam bastante. Então, tudo isso aí já está previsto, alguns já foram adquiridos, tanto para as Regionais de Ensino, como para o órgão central e para as escolas. Então, fez muita diferença sim, aqui para nós mudou muito a nossa prática de promover encontros, fóruns, reuniões, com os equipamentos que nós adquirimos pelo PROMED.

Compreende-se que estes recursos, apesar de poucos, representam um aporte considerável para um nível de ensino que não tinha verbas próprias e que vivia, em grande parte, como anexo do ensino fundamental. Entretanto, os gestores pareciam contentarse com pouco. A ênfase às tecnologias leva a algumas indagações: elas eram efetivamente usadas por professores e alunos? Os docentes estavam preparados para isto? Quais os resultados das ações empreendidas? 
A título de ilustração, o gráfico 1 apresenta uma comparação entre o previsto e o executado no Convênio 097/2001 do PROMED. Por ele é possível perceber que, apesar de este Convênio ter sido programado para execução no triênio 2001/2002/ 2003, ainda existiam componentes com menos de $50 \%$ de suas ações executadas, como Desenvolvimento Curricular, que tinha apenas $46,88 \%$ da sua programação comprovada. Já o componente Rede Física havia empenhado $29,32 \%$ mais do que fora programado, fato que se justificava pela alteração nos preços dos itens adquiridos, uma vez que ainda se encontravam itens em fase de re-licitação, que não foram adquiridos.

\section{Gráfico 1 - Execução orcamentária do PROMED convênio 097/2001.}

\section{Execução PROMED - Convênio 097/2001 (Valores Nominais)}

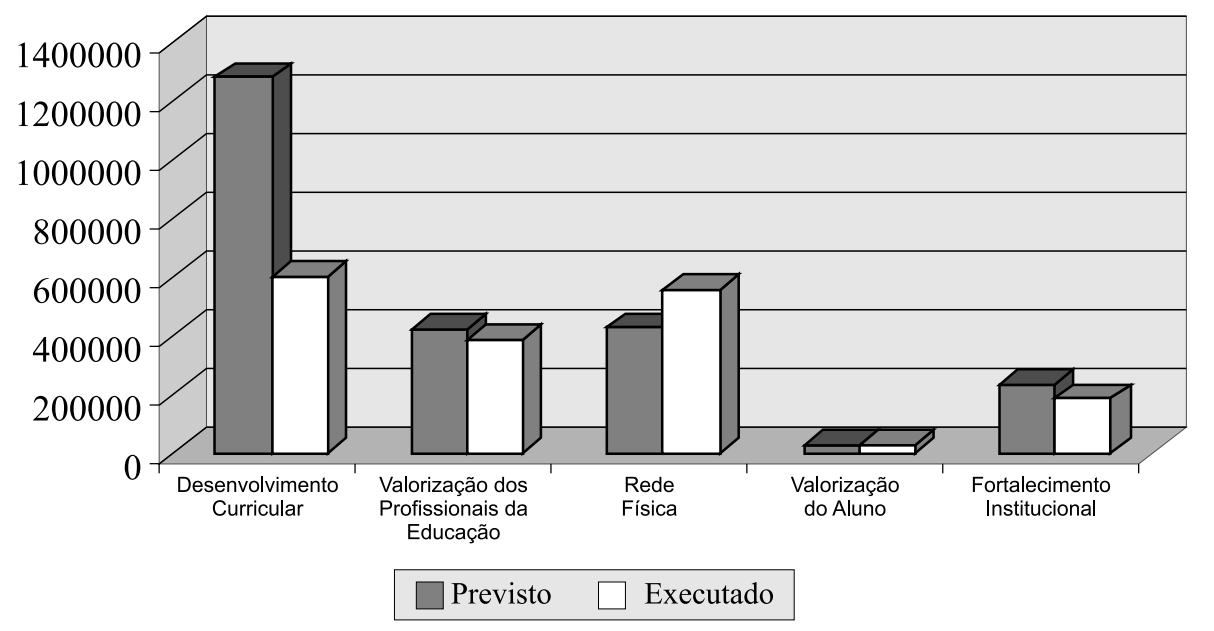

Fonte: DEMTEC e SEDF (2005).

Os componentes Valorização dos Profissionais da Educação, Valorização do Aluno e Fortalecimento Institucional, tiveram, respectivamente $91,62 \%, 97,42 \%$ e 79,55\% de suas programações comprovadas. Assim, enquanto a previsão enfatizou o desenvolvimento curricular, as pessoas e a essência da reforma, a execução acabou por dar predominância à rede física e aos problemas de expansão mais que de aperfeiçoamento. Ou seja, tratou-se de usar os recursos sobretudo para atender à urgência de novas vagas.
Destaca-se que, do montante de R\$ 2.394.941,25, previsto inicialmente para a execução do Convênio 097/2001, foi comprovado, até fevereiro de 2005, a execução de apenas $R \$ 1.756 .710,38$, o que correspondia a 73,35\% do inicialmente previsto para esta primeira fase do Programa.

É importante destacar que, apesar da contribuição que o Programa trouxe para o ensino médio no Distrito Federal, os valores aplicados, se considerados unitaria- 
mente, isto é, por aluno, não foram muito generosos, girando em torno de $R \$ 18,29$, com base no previsto, e $R \$ 12,66$, caso se considere apenas o que já foi efetivamente utilizado. Quanto ao valor empenhado por aluno no Convênio 26/2004, foi de R\$ 27,82, em valores nominais de 2005 .

gráfico 2 mostra a distribuição dos recursos executados entre os diversos componentes da primeira fase do Programa Convênio 097/2001. Nele é possível perceber que o componente Desenvolvimento
Curricular foi o que mais dispôs de recursos, ficando com 34,16\% destes, seguido de perto pelo componente Rede Física, a que foram alocados $31,56 \%$ dos recursos desta etapa do Programa. O componente Valorização dos Profissionais da Educação também dispôs de um percentual considerável dos recursos, $21,99 \%$, seguido pelo Fortalecimento Institucional, que comprovou ser responsável por 10,62\% dos recursos empenhados, e pelo componente Valorização do Aluno, com apenas 1,67\% dos recursos.

\section{Gráfico 2 - Orçamento executado do PROMED convênio 097/2001.}

\section{Execução PROMED - Convênio 097/2001 (Valores Nominais)}

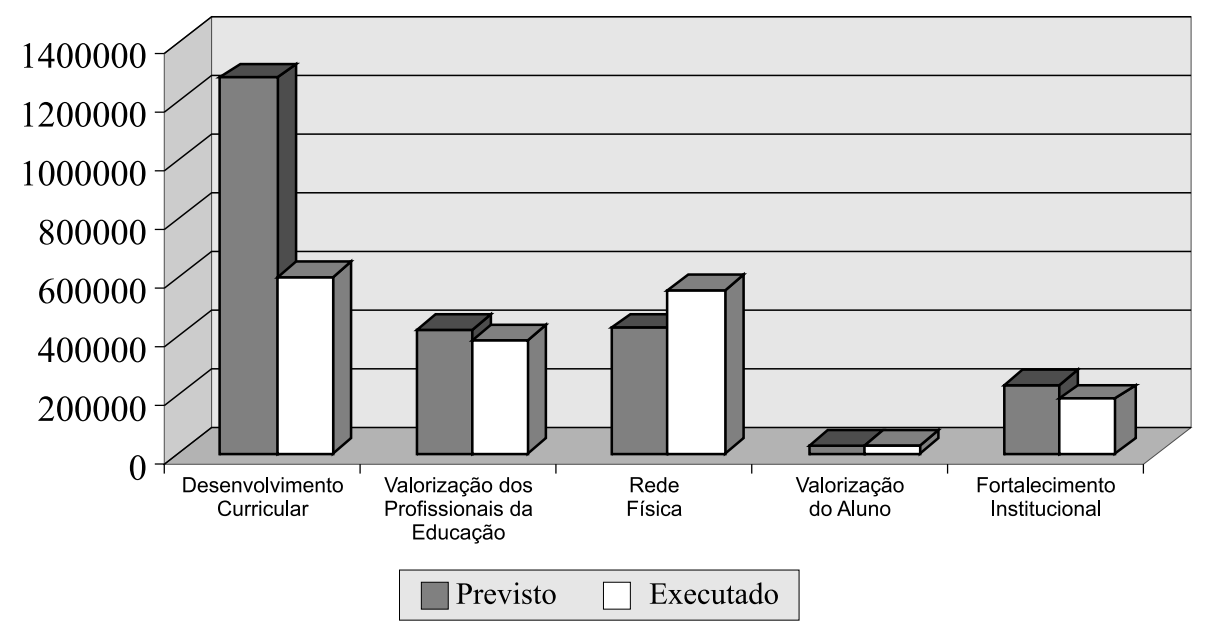

Fonte: DEMTEC e SEDF (2005).

Com isso, a realidade se distanciou das intenções do PROMED, conforme a palavra de uma informante, isto é, "a idéia é a de criar uma nova identidade para o ensino médio, buscar identificar as necessidades destas escolas para que os jovens queiram fazer parte dela, como deve ser uma escola de ensino médio, o que ela deve ter para atrair os adolescentes". 


\section{Recursos versus resultados}

É conhecida a opção de políticas educacionais pelo barato que sai caro: primeiro se trata da quantidade, asseguram-se as vagas, atendendo-se a uma demanda em geral por educação pouco qualificada e satisfazendo-se às demandas eleitorais. Só depois, se e quando há fortes exigências, cuida-se da qualidade. Já se conhecem os resultados deste tiro pela culatra: o que se economiza de um lado se desperdiça do outro no custo da repetência e da baixa qualidade (BEHRMAN; BIRDSALL, 1983). No caso do ensino médio, aproximadamente um entre cada cinco alunos se afasta ao longo do ano letivo, número que, no Nordeste, chega perto de um entre quatro discentes. Ao se comparar os Censos Demográfico e Escolar de 2000, verifica-se que a taxa bruta de escolaridade (total de alunos/ população de 15 a 17 anos de idade) alcançou $76,6 \%$ no pico e caiu para $66,2 \%$ ao fim do ano. No Nordeste estes números foram, respectivamente, de $56,7 \%$ e $47,7 \%$. Quanto ao rendimento escolar, só 6,2\% dos alunos da terceira série do ensino médio pesquisados pelo Sistema de Avaliação da Educação Básica - SAEB, de 2003, alcançaram estágio adequado em Língua Portuguesa e 6,9\% em Matemática. Se o SAEB reprovasse, adotando critérios generosos, $38,6 \%$ dos alunos fracassariam em Língua Portuguesa e 68,8\% em Matemática. $\bigcirc$ Censo Escolar do mesmo ano, entretanto, revela que os professores foram ainda mais generosos: reprovaram $8,2 \%$ dos alunos, embora $12,5 \%$ tivessem sido afastados por abandono, o que, em muitos casos, é uma "reprovação branca", isto é, o aluno sai da escola na expectativa do insucesso. $\bigcirc$ total de perdas seria de pouco mais de um quinto das matrículas. O panorama do SAEB 2005 nada tem de animador.
No caso da rápida expansão do ensino médio, é plausível a hipótese da opção pela quantidade em detrimento da qualidade. Existem evidências na literatura, já mencionadas, de que a qualidade se reduziu, acompanhando a despesa média aluno/ano. Enfim, ter-se-ia colocado mais água no feijão.

No caso do Distrito Federal, aqui focalizado mais de perto, a matrícula entre 1997 e 2003 cresceu 35,2\%, em comparação com $34,7 \%$ para o Brasil. O SAEB capta apenas algumas dimensões da qualidade do ensino (como mensurar os quatro pilares da educação do século XXI: aprender a conhecer, aprender a fazer, aprender a conviver e aprender a ser?). No entanto, a partir dos relatórios publicados do SAEB, entre 1997 e 2003, a média nacional (com todas as suas limitações de medida de tendência central) de Língua Portuguesa para a terceira série do ensino médio caiu 6,1\% e a média de Matemática, 3,5\%. No Distrito Federal os números foram, respectivamente, de 8,4\% e 7,6\%. Em outros termos, o que já era baixo, baixou ainda um pouco mais.

É sedutora a hipótese de que, quanto menos recursos, piores resultados. Se aumentassem os recursos, os escores seriam mais altos. Contudo, o conjunto da literatura internacional não encontra relações significativas entre despesa por aluno e rendimento, entre outros motivos porque o dinheiro pode ser bem ou mal aproveitado; pode ser em grande parte aplicado na escola, em benefício do aluno, mas pode ser desviado para outros fins (e meios). Outro problema é que, ao tentar definir o etéreo conceito de quali- 
dade educacional, utilizam-se insumos necessários que a literatura e o próprio SAEB, desde a sua criação, não detectam como indicadores seguros de maior rendimento discente. Assim, acontece, por exemplo, com a titulação do professor, em certos casos; a formação continuada; a eleição do diretor; a existência de colegiado da comunidade educativa; o número de alunos por turma, o número de alunos por estabelecimento e assim por diante. A questão é complexa e não se encontra uma relação linear e automática entre uma coisa e outra, como menos alunos na sala de aula, maior rendimento; mais horas letivas mais rendimento. Entre outros motivos, porque depende do que se faz na complexa realidade da sala de aula e no tempo letivo, na medida em que este seja mesmo utilizado para o processo educativo (GOMES, 2005).

Além desta discussão sobre o corpus de pesquisa, os dados do Distrito Federal, como os do Ceará (GOMES, 1998) e outros, evidenciam que não é possível confiar plenamente na classificação funcional-programática dos nossos orçamentos e balanços. Cada um dos seus programas parece uma gaveta em que a contabilidade vai distribuindo as despesas com critérios diferentes a cada ano, norteada, é claro, pelo cumprimento de certos critérios formais. No caso do Distrito Federal (e constatações semeIhantes se fazem em outras Unidades Federativas), seria preciso admitir que a despesa média anual por aluno do ensino médio aumentou, em termos reais, 80 vezes entre 1999 e 2001 e, em 2003, se contraiu para $16 \%$ do valor de 2001 (tabela 3). Portanto, como testar realmente a hipótese de que aumentou a matrícula e se reduziu a despesa média por aluno a não ser com estimativas?

\section{No mato sem cachorro?}

Quando o País busca soluções mais duradouras para o financiamento e a alocação de recursos na educação básica, inclusive por meio do FUNDEB, encontra um cipoal de dificuldades. A contabilidade pública, para estes e outros propósitos, não é suficientemente transparente. Na penumbra costumam multiplicarse certos microorganismos, portanto, quanto maiores a luz e a transparência, menores as possibilidades de desvios. A Lei de Diretrizes e Bases (BRASIL, 1996), (arts. $4^{\circ}$, III, e 74), determinou o estabelecimento de um padrão mínimo de oportunidades educacionais, baseado no cálculo do custo mínimo por aluno, capaz de assegurar ensino de qualidade. Na literatura se disseminou o conceito de custo/aluno-qualidade (MONLEVADE, 2001), embora seja muito difícil definir qualidade. Mas como encontrar uma bússola? Os balanços são obviamente deficientes. Já as pesquisas sobre custos constituem terreno um pouco menos lábil (FARENZENA, 2004, 2005). Iniciativas do maior mérito, vários trabalhos têm buscado relacionar custos e condições de qualidade em escolas públicas. Todavia, enfrentam, como não podia deixar de ser, algumas dificuldades. Uma delas é a heterogeneidade de metodologias e a conseqüente comparabilidade: caminhos diferentes levam a pontos de chegada também diferentes. Outro obstáculo é a definição de qualidade com base em variáveis mais ligadas ao processo que aos resultados - e, mais ainda, como foi assinalado, com associações não raro frágeis ou nulas com o que se poderia defi- 
nir como qualidade. Em poucos casos tem sido desagregado o custo/aluno por nível e modalidade de educação e ensino. Antes, se tem trabalhado com o custo/ aluno de cada estabelecimento, geralmente integrante de uma amostra intencional, com unidades às vezes dificilmente comparáveis, ainda que com critérios claramente enunciados. Em certos casos o custo/aluno do ensino médio aparece como mais baixo ou mais alto que o do fundamental. Por quê? Ao se apurar os custos em cada estabelecimento é possível desagregar os dados para obter valores de custo para cada nível e modalidade de educação e de ensino, embora seja complexo e trabalhoso.

Esta, porém, é uma necessidade das políticas públicas. Igualmente, é preciso conhecer melhor o impacto de diversas variáveis sobre os custos. Quanto será o custo/ aluno no ensino médio em estabelecimento que ministre todas as etapas da educação básica? Quanto será naquele que oferece só o ensino fundamental e o médio? E da quinta série do ensino fundamental à última série do médio? Haverá variações significativas entre o ensino regular e a Educação de Jovens e Adultos - EJA? $\bigcirc$ compartilhamento de recursos, relacionado, inclusive, à economia de escala, é economicamente necessário e pedagogicamente, em muitos casos, proveitoso. Ao se operacionalizar o FUNDEB, como proceder com transparência? Os computadores podem gerar uma infinidade de estimativas, conforme os propósitos. Estimativas são aproximações em geral respeitáveis da realidade. Contudo, é insuficiente o retrato da realidade de que dispomos. A transparência se alcança com a simplicidade (não o simplismo), a clareza e o conhecimento profundo da realidade. É indubitável que precisamos avançar muito mais nas pesquisas sobre custos e seus fatores e sobre o financiamento da educação.

Uma esperança tem sido o trabalho de apuração do gasto público pelo Instituto Nacional de Estudos e Pesquisas Educacionais Anísio Teixeira - INEP, Instituto de Pesquisa Econômica aplicada - IPEA e Fundação Instituto Brasileiro de Geografia e Estatística - IBGE, com cálculos realizados a partir dos valores encaminhados para o Programa Mundial de Indicadores Educacionais da Organização de Cooperação e Desenvolvimento Econômicos OCDE. É inevitável o uso da contabilidade pública nacional, no entanto, se observa uma lapidação progressiva dos dados. Assim, refletindo distorções já referidas, o gasto público por aluno do ensino médio, em 1999, correspondeu a 93,1\% de idêntico valor para o ensino fundamental do País e a 97,6\%, no caso do Distrito Federal (ALMEIDA, 2001). Desse modo, o ensino médio seria mais "barato" que o fundamental. Os últimos dados, de 2002, ainda não desagregados, apontam para o gasto público anual por aluno, no Brasil, de R\$ 824 para a primeira à quarta série do ensino fundamental, $\mathrm{R} \$ 925$ para as séries finais do ensino fundamental e $R \$ 941$ para o ensino médio (BRASIL, 2006). $\bigcirc$ segundo valor é 12,3\% maior que o primeiro e o último, do ensino médio, é 1,7\% maior que o segundo. A realidade parece se delinear com maior nitidez, como num espelho que reflete melhor as imagens. Que a perseverança continue guiando o aperfeiçoamento dos dados. De outro modo, estaremos realmente no mato sem cachorro. 


\section{Referências}

ALMEIDA, I. C. Gastos com educação no período de 1994 a 1999. Revista Brasileira de Estudos Pedagógicos, Brasília, DF, v. 82, n. 200/201/202, p. 137-198. jan./dez. 2001.

BEHRMAN, J. R.; BIRDSALL, N. The quality of schooling: quantity alone is misleading. American Economic Review, Nashville, v. 73, n. 5, p. 928-946, dez. 1983.

BRASIL. Ministério da Educação. Gasto público por aluno, segundo níveis de ensino. Disponível em: <http://www.inep.gov.br/download/estatisticas/gasto_educacao/ tabelas_xls/GP_PorAluno_NiveisEnsino_BR2000_2002.xls. >. Acesso em: 8 abr. 2006.

CASTRO, J. A.; DUARTE, B. C. Estimativas dos custos associados ao atendimento da demanda pelo ensino médio, em consonância às metas estabelecidas para o Plano Nacional de Educação para o período de 2003 a 2011 . [S.I.: s.n., 2003?].

CAVALCANTE, A. F. Ensino público: gratuito, em termos - custos indiretos do ensino médio para os alunos das escolas públicas do Distrito Federal. Em Aberto, Brasília, DF, v. 19, n. 75, p. 113-122, jul. 2002.

COSTA, V. L. C. Financiamento e gasto com o ensino médio no Brasil. Em Aberto, Brasília, DF, v. 18, n. 74, p. 72-80, dez. 2001.

DAVIES, N. Ensino médio estatal: menos verbas para mais alunos? Trabalho, Educação e Saúde, Rio de Janeiro, v. 2, n. 1, p. 153-178, mar. 2004.

FARENZENA, N. (Coord.). Levantamento do custo aluno/ano em escolas de educação básica que oferecem condições para oferta de ensino de qualidade: Rio Grande do Sul: relatório de pesquisa. Porto Alegre: UFRGS, FACED, Núcleo de Estudos de Política e Gestão da Educação, 2004.

FARENZENA, N.; VIEIRA, S. L. et al. (Org.). Custos e condições de qualidade da educação escolas públicas: aportes de estudos regionais. Brasília, DF: INEP, MEC, 2005.

GOMES, C. A. A educação em novas perspectivas sociológicas. 4. ed. São Paulo: Ed. Pedagógica e Universitária, 2005.

Financiamento e eqüidade. In: GOMES, C. A.; AMARAL SOBRINHO, J. (Org.). Qualidade, eficiência e eqüidade na educação básica. Brasília, DF: IPEA, 1992.

Quanto custa a expansão do ensino médio. Cadernos Unesco Brasil, Brasília,

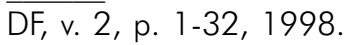

Regime de colaboração intergovernamental: alternativa para a maioridade do ensino médio. Cadernos de Pesquisa: revista da Fundação Carlos Chagas, São Paulo, n. 109, p. 25-42, mar. 2000. 
MALDI, R. M. N.; GOMES, C. A. O financiamento do Ensino médio público no nível escolar: o Patinho Feio ainda à espera de se tornar cisne. Ensaio: avaliação e políticas públicas em educação: revista da Fundação Cesgranrio, Rio de Janeiro, v. 11, n. 40, p. 314-331. jul./set.2003.

MONLEVADE, J. Educação pública no Brasil: contos e descontos. 2. ed. Ceilândia, DF: Idéia Ed., 2001.

MORGADO, P. C. C. R. O processo de financiamento do ensino médio público no Distrito Federal. 2006. Dissertação (Mestrado em Educação)-Universidade Católica de Brasília, Brasília, DF, 2005. Disponível em <http://www.ucb.br>. Acesso em: jul. 2006.

PINTO, J. M. R. Financiamento do ensino médio no Brasil: uma abordagem inicial. Trabalho, Educação e Saúde, Rio de Janeiro, v. 2, n. 1, p. 135-151, mar. 2004.

SANTOS, J. O orçamento dos CEFETS e das ETFS: praticando a política do cobertor curto. Trabalho, Educação e Saúde, Rio de Janeiro, v. 2, n. 1, p. 179-188, mar. 2004.

Recebido em: 03/08/2006

Aceito para publicação em: 09/05/2007 